\title{
ORDER REDUCTION OF DISCRETE-TIME ALGEBRAIC RICCATI EQUATIONS WITH SINGULAR CLOSED LOOP MATRIX
}

\author{
Augusto Ferrante ${ }^{1}$ AND Harald K. Wimmer
}

\begin{abstract}
We study the general discrete-time algebraic Riccati equation and deal with the case where the closed loop matrix corresponding to an arbitrary solution is singular. In this case the extended symplectic pencil associated with the DARE has 0 as a characteristic root and the corresponding spectral deflating subspace gives rise to a subspace where all solutions of the DARE coincide. This allows for a reduction of the original DARE to an equation of smaller size.
\end{abstract}

Mathematics subject classification (2000): 15A24, 93C55, 93B11.

Key words and phrases: Discrete-time algebraic Riccati equation, closed loop matrix, symplectic matrix pencil, deflating subspaces, order reduction.

\section{REFERENCES}

[1] H. Abou-Kandil, G. Freiling, V. Ionescu And G. Jank, Matrix Riccati Equations in Control and Systems Theory, Birkhäuser, Basel, 2003.

[2] H. BaumgärTEl, Analytic Perturbation Theory for Matrices and Operators, Birkhäuser, Basel, 1985.

[3] S. Bittanti, A. J. Laub And J. C. Willems, eds., The Riccati Equation, Springer, Berlin, 1991.

[4] D. C. ClEMENTS AND H. K. WIMMER, Existence and uniqueness of unmixed solutions of the discrete-time algebraic Riccati equation, Systems Control Lett. 50 (2003), pp. 343-346.

[5] T. FuJinakA, G. CHEN AND H. SHIBATA, Discrete algebraic Riccati equation with singular coefficient matrix, Proceedings of the MTNS-98 Symposium on the Mathematical Theory of Networks and Systems, A. Beghi, L. Finesso and G. Picci, eds., Il Poligrafo, Padova 1998, pp. 625-628.

[6] F. R. GANTMACHER, The Theory of Matrices, Vol. II, Chelsea, New York, 1959.

[7] I. Gohberg, S. GoldBerg AND M. A. KAASHOEK, Classes of Linear Operators, vol. I, Operator Theory: Advances and Applications, Vol. 49. Birkhäuser, Basel, 1990.

[8] I. GOHBERG, P. LANCASTER AND L. RodmAn, Invariant Subspaces of Matrices with Applications, Wiley, New York, 1986.

[9] CH.-H. GUO, Newton's method for discrete algebraic Riccati equations when the closed-loop matrix has eigenvalues on the unit circle, SIAM J. Matrix Anal. Appl. 20 (1998), pp. 279-294.

[10] G. HASSIBI, A. H. SAYED AND TH. KAILATH, Indefinite-quadratic Estimation and Control: A Unified Approach to $\mathscr{H}_{2}$ and $\mathscr{H}_{\infty}$ Theories, SIAM Studies in Applied Mathematics, Vol. 16, SIAM, Philadelphia, 1999.

[11] V. IONESCU, M. WEISS, On computing the stabilizing solution of the discrete-time Riccati equation, Linear Algebra Appl. 174 (1992), pp. 229-238.

[12] P. LanCASter And L. Rodman, Algebraic Riccati Equations, Clarendon Press, Oxford, 1995.

[13] Th. PAPPAS, A.J. LAuB AND N.R. SANDELl, JR., On the numerical solution of the discrete-time algebraic Riccati equation, IEEE Trans. Automat. Control 25 (1980), pp. 631-641.

[14] P. VAn DoOREN, A generalized eigenvalue approach for solving Riccati equations, SIAM J. Sci. Statist. Comput. 2 (1981), pp. 121-135. 